\title{
Erratum to: Prevention of Lower Eyelid Ectropion Using Nonincisional Suspension Sutures after Blepharoplasty
}

So Min Hwang ${ }^{1}$, Sang-Hwan Lee ${ }^{1}$, Kyoung-Seok $\mathrm{Oh}^{2}$, Hyung-Do Kim ${ }^{1}$, Yong-Hui Jung ${ }^{1}$, Hong-Il Kim ${ }^{1}$

${ }^{1}$ Aesthetic, Plastic \& Reconstructive Surgery Center, Good Moonhwa Hospital, Busan; ${ }^{2}$ Dr. OH Plastic Surgery, Daegu, Korea

Arch Aesthetic Plast Surg 2014;20(3):173-177

In this article, on page 173, the title has been spelled incorrectly in this article: "Noninsional" should have appeared as "Nonincisional".

The name of author should be corrected as the following:

from "Min Hwang" to "So Min Hwang"

We apologize for any inconvenience caused.

Copyright $\odot 2015$ The Korean Society for Aesthetic Plastic Surgery.

This is an Open Access article distributed under the terms of the Creative Commons Attribution Non-Commercial License (http://creativecommons.org/licenses/by-nc/3.0/) which permits unrestricted non-commercial use, distribution, and reproduction in any medium, provided the original work is properly cited. www.e-aaps.org 